TITLE:

\title{
Reports from the Field : Kabarole, Uganda: A Human Infant Killed by a Wild Chimpanzee?
}

$\operatorname{AUTHOR}(\mathrm{S})$ :

\section{CITATION:}

Reports from the Field: Kabarole, Uganda : A Human Infant Killed by a Wild Chimpanzee?. Pan Africa News 1996, 3(1): 5-6

ISSUE DATE:

1996-06

URL:

http://hdl.handle.net/2433/143334

RIGHT:

Copyright (C) Pan Africa News. 


\section{A HUMAN INFANT KILLED BY A WILD CHIMPANZEE?}

According to Mr. Christopher Bakuneeta, Budongo Forest Project, Masindi, Uganda, the surprising news of the death of an human infant due to an attack by a wild chimpanzee was reported by the Government newspaper New Vision 256 (November 6, 1995). Mr. Bakuneeta summarized the tragic event in a letter to PAN and his comments are given below. The death of the infant allegedly occured on November 2, 1995 while the victim's mother was absorbed in cultivating her farmland and the baby slept alone near the field. The mother tried to save her baby but her efforts were in vain.

"In my personal opinion, the very chimpanzee who killed the baby might be one of those habituated by human researchers," Mr. Bakuneeta wrote. "This tragedy might have been caused by the overhabituation of study chimps. They have been so much used to the researchers 
and assistants that they can become quite aggressive and dangerous."

Mr. Bakuneeta was concerned because according to the National Park/Game Act in Uganda, no compensation could be given to the family even if his speculation turned out to be true. In particular, he feared that the feelings brought forth by such a report might change the tolerant attitude that local people maintain toward the study chimps. "For instance, the Budongo Forest chimpanzees have acquired a good feeling within the neighbouring communities near the Reserve. People are tolerant even when the chimps eat a few of their crops while they chase away the baboons which are more destructive. Such a tragedy may sever the good relationships between the habituated chimps and local people."

Professor Toshisada Nishida of Kyoto University was asked to comment on the report in the Ugandan newspaper.

"Dr. Bakuneeta informs us of the rare event of a human infant killed by a wild chimpanzee. So far as I know, such a case has only been reported by Goodall for the chimpanzees near Gombe, Tanzania," said Professor
Nishida. "Dr. Bakuneeta suggests that the killer chimpanzee came from a habituated population. However, I do not think this is based on sound evidence or reasonable speculation. First, Gombe's case occurred long before Goodall succeeded in the habituation of her chimpanzees. Second, it is true that some chimpanzees increasingly use intimidation displays in the presence of and even attack human observers as habituation makes progress. However, there is no evidence that chimpanzees who are accustomed to humans become more likely to kill and eat human infants. Chimpanzees are predators from the onset. Habituation does not bring out their carnivorous tendency. Wild chimpanzees apparently kill and eat any medium-sized mammal from 1 to $10 \mathrm{~kg}$ in size. Human observers should not leave their infants or small children alone in their camp if wild chimpanzees regularly visit it. This has been a common sense rule that has long been observed by researchers of Mahale, and very probably Gombe."

Ed.note: The editorial office of PAN is now trying to obtain information on this event. We would like to ask any one of you who has any relevant information to contact us by letter or e-mail. 